\title{
The Use of 3D Titanium Miniplates in Surgical Treatment of Patients with Condylar Fractures
}

\author{
Maciej Sikora ${ }^{1,2}\left(\mathbb{D}\right.$, Maciej Chęciński $^{3}\left(\mathbb{D}\right.$, Marcin Sielski $^{1}$ and Dariusz Chlubek ${ }^{2, *(1)}$ \\ 1 Department of Maxillofacial Surgery, Hospital of the Ministry of Interior, Wojska Polskiego 51, \\ 25-375 Kielce, Poland; sikora-maciej@wp.pl (M.S.); marcinsielski@gazeta.pl (M.S.) \\ 2 Department of Biochemistry and Medical Chemistry, Pomeranian Medical University, \\ Powstańców Wlkp. 72, 70-111 Szczecin, Poland \\ 3 STOMADENT Non-public Healthcare Institution, Dental Clinic, Kościuszki 32, 46-320 Praszka, Poland; \\ maciej@checinscy.pl \\ * Correspondence: dchlubek@pum.edu.pl
}

Received: 18 August 2020; Accepted: 9 September 2020; Published: 10 September 2020

check for updates

\begin{abstract}
The aim of this study was to evaluate the effectiveness of open treatment of mandibular condyle fractures using 3D miniplates. A group of 113 patients has been chosen for evaluation, including 100 men and 13 women. After hospitalization, each patient underwent a 6-month postoperative follow-up. The material chosen for the analysis consisted of data collected during the patient's stay in the hospital as well as the postoperative outpatient care. A single 4-hole Delta Condyle Compression Plate (4-DCCP) was used in 90 out of $113(79.6 \%)$ cases. In 16 out of $113(14.2 \%)$ patients, the Trapezoid Condyle Plate (4-TCP or 9-TCP) was used. The remaining cases required more than one miniplate. No 3D miniplate fractures were found in the study subjects during the analyzed observation period. Loosening of one or more osteosynthesis screws was observed in 4 out of 113 $(3.5 \%)$ patients. Screw loosening was a complication that did not affect bone healing in any of the patient cases. The conducted research confirms that titanium 3D mini-plates are easy to adjust and take up little space, therefore they can easily be used in cases of mandibular condyle base and lower condyle neck fractures. The stability of the three-dimensional miniplates for osteosynthesis gives very good reliability for the rigid fixation of the fractured mandibular condyle.
\end{abstract}

Keywords: 3D miniplates; condylar fractures; internal fixation; mandibular condyle fractures; open reduction

\section{Introduction}

Mandibular condyle fractures are a heterogeneous group of fractures which classification and methods of therapy are constantly improving [1-3]. According to various studies, the incidence of condylar fractures among all mandibular fractures is $23 \%$ to $35 \%[4,5]$. Means of treating condylar fractures can be broken down into closed and open treatment methods. All treatment strategies listed include subsequent functional therapy, and each of them can be supplemented with maxillo-mandibular fixation [6-8]. Despite creating a risk of injury to the facial nerve with surgical access the closed treatment approach is not exempt from disadvantages having less functional results in comparison [9]. There are also voices indicating that both strategies (closed treatment vs. open treatment) are not easily comparable [10].

Recent years have brought clear guidelines indicating appropriate surgical approaches depending on the location of the fracture gap [1-3,11]. Materials that are typically used for assessing base of the condyle and lower part of the mandible neck fractures are miniplates fixed to the bone surface with screws $[2,12,13]$. The most common types are straight plates with linear arrangement of holes, 
L-shaped plates and multidimensional plates (3D plates) [7,14]. It has been proved that use of a single straight or L-shaped plate presents less satisfactory mechanical properties than using of two plates (double plate technique) or a single 3D plate [14,15]. These include Strut, Rhombic, Trapezoid (TCP), Delta (DCCP), Lambda, A-shape (ACP) and X-shape (XCP) patterns [7,16-18]. There are also miniplates made of resorbable materials (e.g., PLLA, PDLLA), but their use is still not common due to the lower mechanical strength than that presented by their metal counterparts $[19,20]$. In the search for the most suitable materials for making 3D miniplates, numerous in vitro and animal tests are carried out, focusing mainly on areas of mechanical strength and body response [17,21-23]. The future solution may be fixation elements prepared for an individual patient [24,25].

\section{Aim of the Study}

This study was designed to assess the effectiveness of open treatment of mandibular condyle fractures using 3D miniplates. The paper summarizes a prospective cohort observational study at one institution.

\section{Materials and Methods}

This study was conducted in the Department of Maxillofacial Surgery, Hospital of the Ministry of Interior in Kielce (Poland), in accordance with the Declaration of Helsinki. All procedures involving human subjects were approved by the Ethics Committee of the Pomeranian Medical University in Szczecin (Approval No. KB-0012/43/06/2020/Z). Written informed consent was obtained from all subjects.

One hundred and thirteen patients (100 men and 13 women) operated on during the years 2013-2019 were included in the study and qualified in accordance with the date of the beginning of the therapeutic process. To our knowledge, the study group presented in this article is the second largest group indexed in PubMed for 3D miniplates. After the hospitalization, each patient was subjected to 6 months postoperative observation, which was equal to the evaluation period. Data regarding the period of stay in the hospital and collected during postoperative ambulatory care was used as material for analysis.

Classification of the condylar fractures performed for the purposes of this study was conducted according to the Comprehensive AOCMF Classification System [2] which derives from the earlier division of Loukota et al. [3].

The diagnosis in each case in the study group was based on a clinical examination and radiographs in panoramic and PA projections. Whenever these methods were insufficient, computed tomography (CT) scans were performed. The same diagnostic protocol was used postoperatively to control the position of the fragments. The value of three-dimensional diagnostics for full visualization of details is also appreciated by other authors [26].

Detailed criteria for inclusion to the study and exclusion from the study group are presented in Tables 1 and 2.

Table 1. Criteria for including patients in the study.

\section{Qualification Criteria}

(1) Fracture in the anatomical region of the base and/or neck of the condyle of the mandible according to the AOCMF Classification System [2]

(2) At least one of the following criteria:
(a) presence of occlusal disorders
(b) reduction of the vertical dimension of the mandible ramus by at least $4 \mathrm{~mm}$ due to displacement and overlapping of fragments
(c) comminuted fracture
(d) dislocation of the condyle in the temporomandibular joint
(e) no contact between bone fragments

(3) Age greater than or equal to 18 years 
Table 2. Criteria for excluding patients from the study.

\section{General Exclusion Criteria}

(1) Lack of patient's consent to open treatment

(2) Contraindications for treatment under general anesthesia expressed in categories IV-VI on the ASA

Physical Status Classification System scale

\section{Local Exclusion Criteria}

Mandibular head fracture according to the AOCMF Classification System [2] - the course of any fragment of the fracture line above the reference line of the head of the mandible

Standard epidemiological data were collected for each patient during medical interview, clinical examination, hospitalization and postoperative ambulatory care. For this purpose, the form shown in Table 3 was used.

Table 3. Medical interview and examination form.

\begin{tabular}{|c|c|}
\hline \multicolumn{2}{|c|}{$\begin{array}{l}\text { Patient Number } \\
\text { Medical Interview }\end{array}$} \\
\hline Sex & Male/Female \\
\hline Age & $\ldots$ \\
\hline Age range & $18-30 / 31-40 / 41-50 / 51-60 / 61-70 / 71-80$ \\
\hline Residence & $\begin{array}{l}\text { Village and town below } 20 \mathrm{k} / \text { Medium town from } 20 \mathrm{k} \\
\text { to } 100 \mathrm{k} / \text { Big city over } 100 \mathrm{k}\end{array}$ \\
\hline Tobacco use & $\begin{array}{l}\text { Not applicable/Up to } 10 \text { cigarettes a day/11-20 } \\
\text { cigarettes a day/More than } 20 \text { cigarettes a day }\end{array}$ \\
\hline Alcohol consumption & $\begin{array}{c}\text { Not applicable/Occasionally (less than once a } \\
\text { week)/Frequently (1-3 times a week)/Alcohol } \\
\text { dependence (more than } 3 \text { times a week) }\end{array}$ \\
\hline Cause of injury & $\begin{array}{c}\text { Violence effect/Fall and impact/Traffic accident/Sports } \\
\text { accident/Others }\end{array}$ \\
\hline Time from trauma to surgery, days & \\
\hline Time range from trauma to surgery & Up to 3 days/4-10 days/More than 10 days \\
\hline \multicolumn{2}{|c|}{ Clinical Examination } \\
\hline $\begin{array}{c}\text { Classification of missing teeth according to } \\
\text { Eichner [27] }\end{array}$ & $\begin{array}{l}\text { Full dental arches (A1)/Supporting zones preserved } \\
\text { (A2, A3)/Missing supporting zones (B1, B2, B3, B4, C1, } \\
\text { C2)/Toothlessness (C3) }\end{array}$ \\
\hline Coexisting mandibular fracture & $\begin{array}{c}\text { Not applicable/Opposite condylar } \\
\text { process/Mandibular angle/Mandibular body/Other } \\
\text { mandibular fracture }\end{array}$ \\
\hline Coexisting fracture of other facial bones & $\begin{array}{c}\text { Not applicable/Zygomatic bone/Maxilla/Nasal } \\
\text { skeleton/Other location/Fractures of multiple bones } \\
\text { Not }\end{array}$ \\
\hline Coexisting soft tissue injuries & $\begin{array}{c}\text { applicable/Ecchymosis/Wound/Oedema/Combination } \\
\text { of the above }\end{array}$ \\
\hline Type of condylar fracture & Simple/Comminuted \\
\hline Localization of the condylar fracture & Condylar base/Lower portion of the condylar neck \\
\hline Displacement of bone fragments & $\mathrm{No} /$ Yes \\
\hline Dislocation in the temporomandibular joint & No/Yes \\
\hline
\end{tabular}

The open reduction and internal fixation (ORIF) surgery was performed under general anaesthesia. All fractures were rigidly fixed with standard three-dimensional (3D) Medartis Modus 2.0 plates. Detailed data on the 3D plates used is presented in Table 4. 
Table 4. Characteristics of 3D plates used in the study.

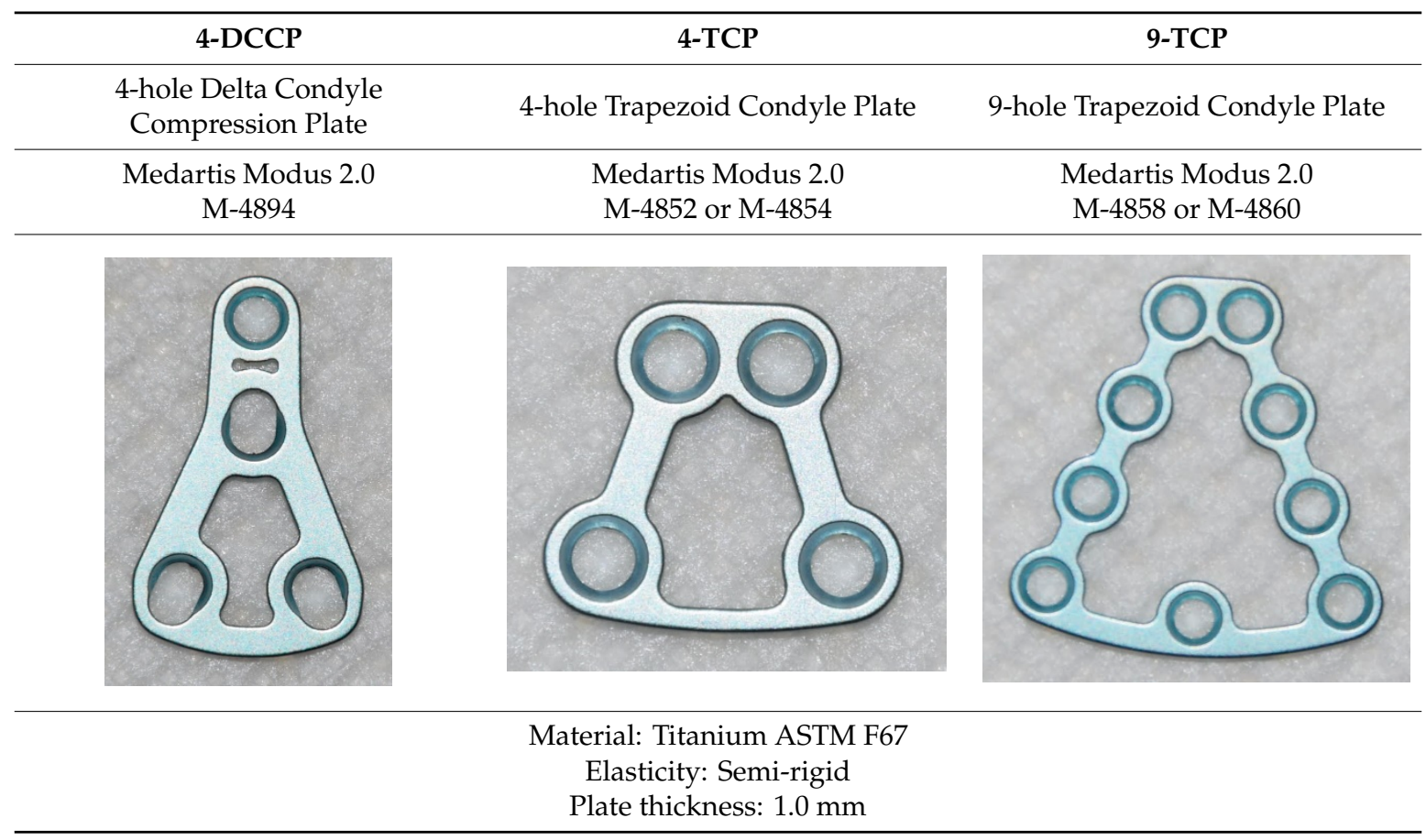

During postoperative examination the maximum jaw opening was measured, the facial nerve function was assessed, the condition of the temporomandibular joints was examined, control X-rays were performed to assess bone healing and the state of the fixing material. The entire diagnostic and therapeutic process of patients was in accordance with current guidelines. Both surgery and all pre- and postoperative examinations were performed on patients in accordance with the standard procedure that is performed on patients with this type of injury. The form for collecting data during the operation and the postoperative observation period is presented in Table 5.

Table 5. Observation form.

\begin{tabular}{|c|c|}
\hline \multicolumn{2}{|c|}{ Hospitalization } \\
\hline Surgical approach & $\begin{array}{l}\text { Intraoral/Retromandibular } \\
\text { transparotid/Submandibular }\end{array}$ \\
\hline 3D plate used & 4-DCCP/4-TCP/9-TCP/more than one plate \\
\hline Duration range of the operation & $\begin{array}{l}\text { Less than } 30 \mathrm{~min} / 30-60 \mathrm{~min} / 60-120 \mathrm{~min} / \text { More than } \\
\qquad 120 \mathrm{~min}\end{array}$ \\
\hline Hospitalization time range & $1-3$ days/4-10 days/More than 10 days \\
\hline \multicolumn{2}{|c|}{ Outpatient Control After 6 Months } \\
\hline $\begin{array}{l}\text { Assessment of facial nerve dysfunction according to } \\
\text { House and Brackmann scale [28] }\end{array}$ & $\begin{array}{l}\text { Normal function (I)/Mild dysfunction (II)/Moderate } \\
\text { dysfunction (III)/Moderately severe dysfunction } \\
\text { (IV)/Severe dysfunction (V)/Total paralysis (VI) }\end{array}$ \\
\hline Interincisal mouth opening, $\mathrm{mm}$ & $\ldots$ \\
\hline Plate breakage & Yes/No \\
\hline Screw loosening & Yes/No \\
\hline Malocclusion & Yes/No \\
\hline Temporomandibular joints disorders (i.e., clicking) & $\begin{array}{c}\text { Not applicable/Transient (up to } 6 \text { months)/Persistent } \\
\text { (over } 6 \text { months) }\end{array}$ \\
\hline
\end{tabular}

\section{Results}

Patients were classified into six age categories (Figure 1) The causes of injuries for the entire study group are illustrated in Figure 2. Due to the more numerous male population, the distribution of injury 
causes for the whole group largely corresponds to the distribution of injury causes specified for the group of men. The time interval from trauma to surgery is shown in Figure 3. This time depended most on the time between trauma and admission to the maxillofacial surgery department. The delay in starting surgical treatment consisted mainly of delayed patient reporting to any medical facility and the procedure of transferring the patient to our hospital.

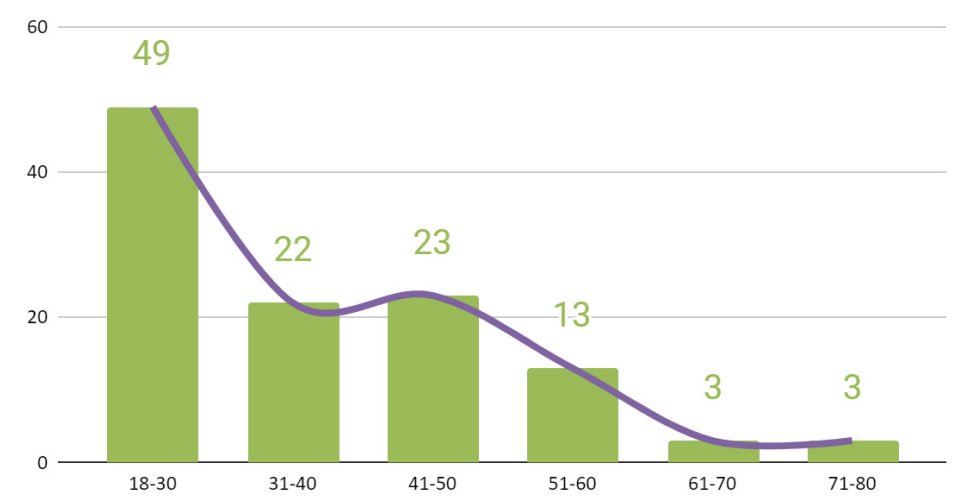

Figure 1. Classification of all patients in accordance to age range.

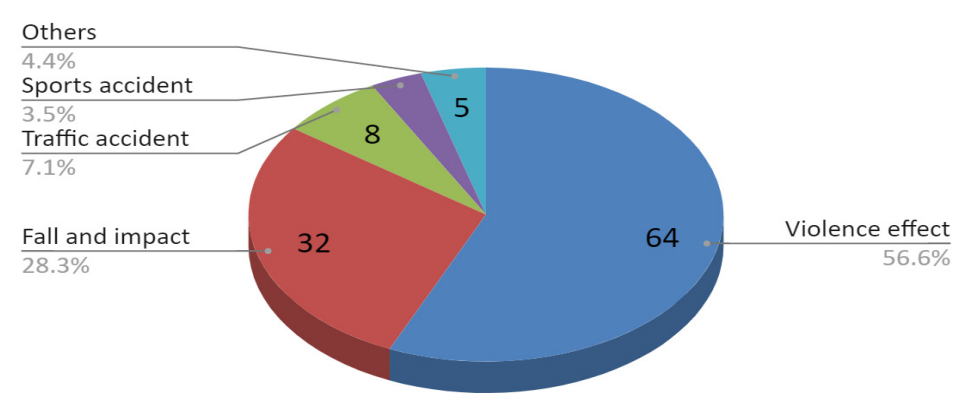

Figure 2. The causes of injuries for the entire study group.

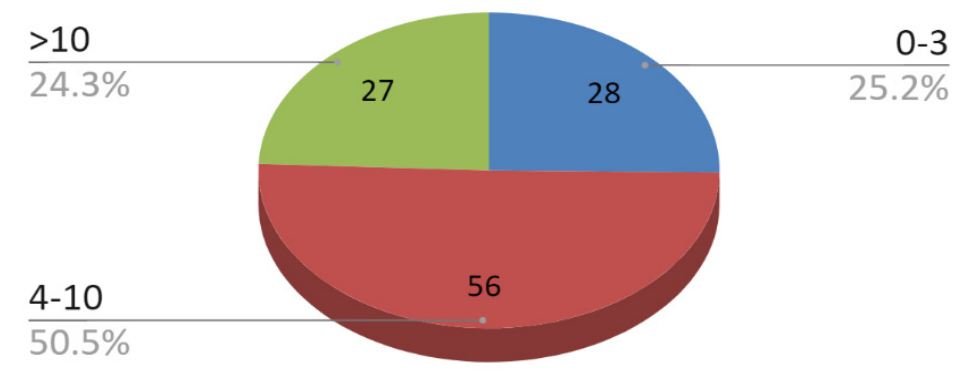

Figure 3. Time interval from trauma to surgery.

The dentition status of the patients divided into four clinically significant categories is shown in Figure 4. Forty seven (47) of the 113 (41.6\%) patients had full dental arches (1). Among patients with incomplete dental arches, three groups were distinguished: (2) with preserved support zones (supporting), (3) with partially or completely lost support zones (Non-supporting) - and (4) edentulous (toothlessness). The numbers in brackets correspond to these on the vertical axis of the graph depicted in Figure 5. This graph shows a correlation between the age of patients and their dental condition defined in the four categories mentioned above. The observed correlation takes the value of Pearson's coefficient equal to 0.50 .

The next data refers to the nature of the injury suffered. According to the pie chart in Figure 6,76 of $113(67.3 \%)$ patients tested had multiple mandible fractures. Thirty seven (37) out of the $113(32.7 \%)$ subjects were diagnosed with isolated fractures of one condylar process. In the group of patients who suffered a multi-site fracture of the mandible, the majority of fractures covered two locations. In 50 of all $113(44.2 \%)$ patients with condylar fracture, concomitant fractures included the body or the angle 
of the mandible. Bilateral fractures of the mandibular condyle processes without other coexisting fractures within this bone were rare. Such a fracture was reported only in 4 out of 113 (3.5\%) patients. A group of 22 out of $113(19.5 \%)$ subjects had a different combination of fractures, including concomitant alveolar fracture, mandibular branch fractures, and, most of all, complex fractures involving more than two locations.

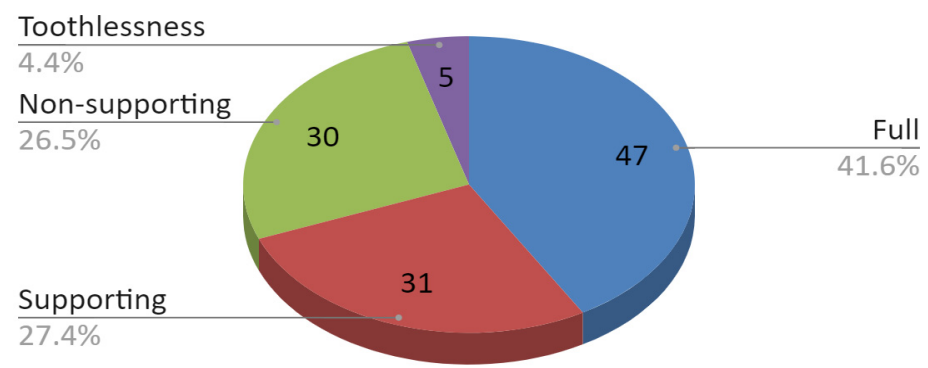

Figure 4. Dentition status of the patients.

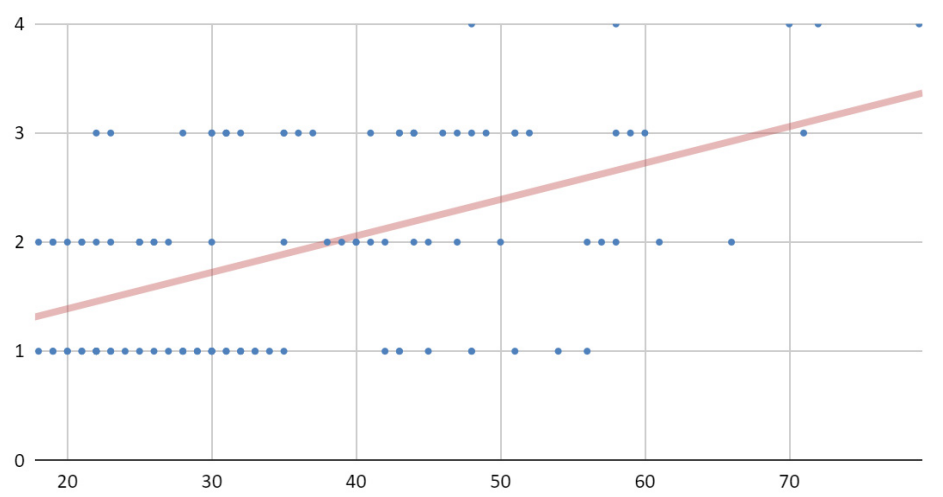

Figure 5. The correlation between the age of the patients and their dental condition. Description in the text.

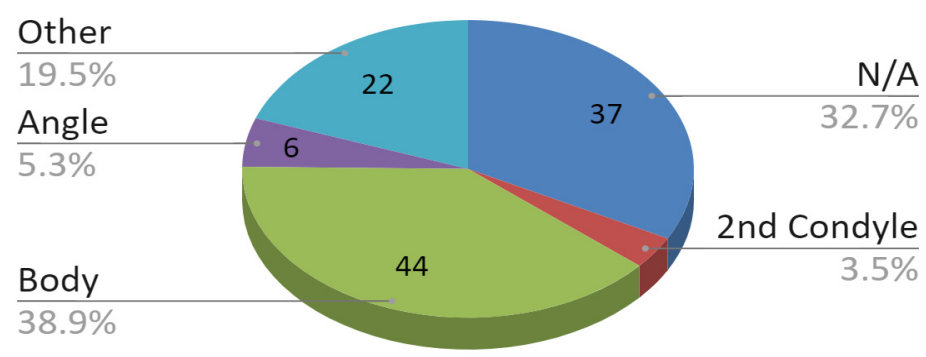

Figure 6. Concomitant fractures of the mandible.

About $80 \%$ of the fractures, which included the condylar process fracture, were solely in the mandible. The remaining 23 of $113(20.4 \%)$ fractures involved more than one bone. A detailed division of coexisting non-mandibular bone fractures is shown in Figure 7. In this group, fractures of three or more bones predominated, i.e., mandible and at least two other bones. In turn, the pie chart in Figure 8 illustrates coexisting soft tissue injuries. In about half of the cases, they were composite injuries. Only in eight out of $113(7.1 \%)$ examined patients no soft tissue injuries were found in physical examination.

Eighty eight (88) out of the $113(77.9 \%)$ cases concerned the base of the condylar process according to the classification AOCMF Classification System [2]. The remaining 25 of 113 (22.1\%) were low mandible neck fractures according to the same classification. As many as 99 out of $113(87.6 \%)$ condylar fractures were displaced. About a quarter of all fractures involved mandibular head dislocation outside the acetabulum. This means that 30 of $99(30.3 \%)$ displaced fractures were dislocated. 


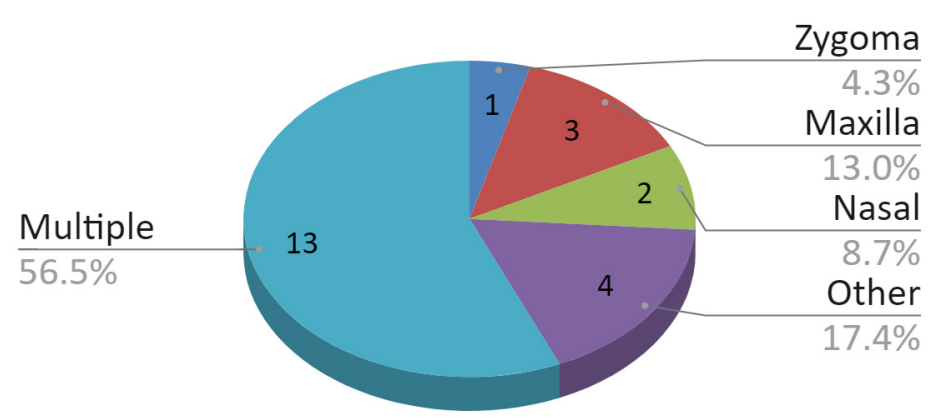

Figure 7. Division of coexisting non-mandibular bone fractures.

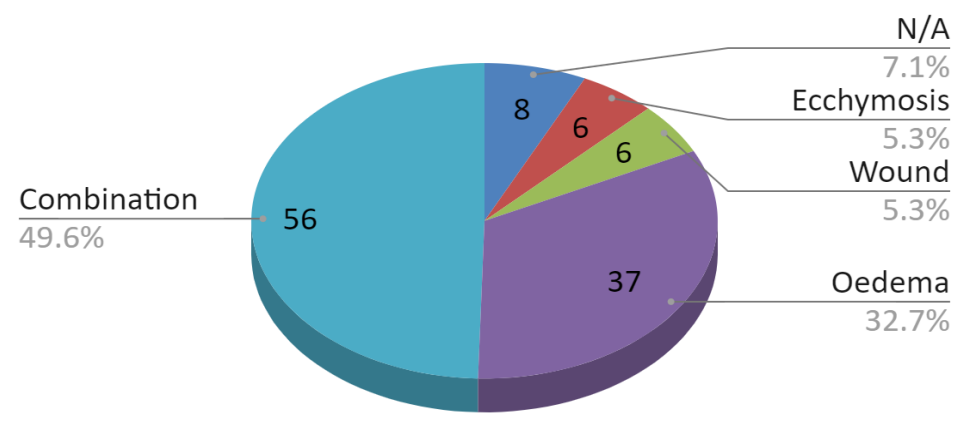

Figure 8. Coexisting soft tissue injuries.

The information discussed below concerns the patient's stay in the hospital ward. The vast majority $(94.7 \%)$ of patients were operated using a retromandibular transparotid approach. In the remaining patients, surgeons decided to use intraoral (4.4\%) and submandibular approaches $(0.9 \%)$. In 90 of $113(79.6 \%)$ cases, a single 4-hole Delta Condyle Compression Plate (4-DCCP) was used. In 16 of $113(14.2 \%)$ patients it was decided to use a trapezoidal plate (4-TCP or 9-TCP). Seven out of 113 $(6.2 \%)$ mandibular condylar fractures required the use of more than one mini-plate.

The time interval of the operation is shown in Figure 9. It was dependent, inter alia, on the extent of the injury. The vast majority of patients (68.1\%) stayed in the ward from 4 to 10 days, $25.7 \%$ stayed for 1-3 days, longer hospitalizations (>10 days) concerned only seven out of $113(6.2 \%)$ patients.

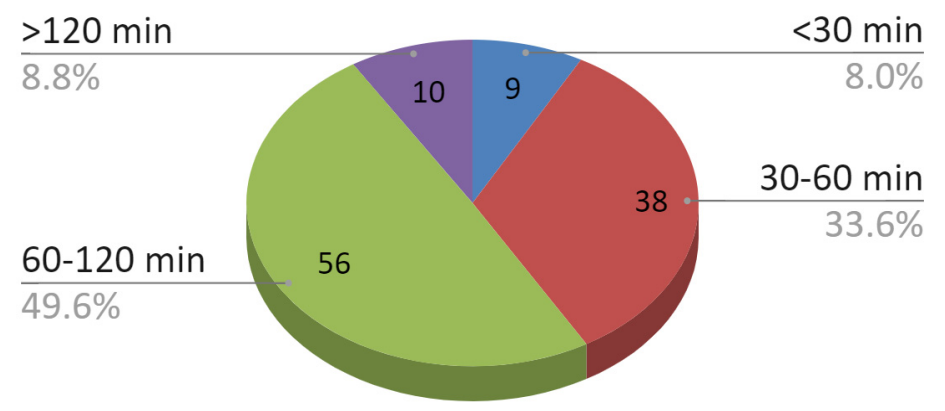

Figure 9. Duration of individual operations.

The following data reflects the results of the examination of patients 6 months after individual operations. According to the House and Brackmann scale [28], 106 out of 113 (93.5\%) subjects recovered the full facial nerve function (I Grade). Out of the remaining seven patients, five (4.4\%) showed a mild dysfunction of one or more of the facial nerve branches, noticeable on close inspection (Grade II). Obvious dysfunction of one or more branches of the facial nerve that did not lower the patient's quality of life persisted 6 months after surgery in two out of $113(1.8 \%)$ patients (Grade III).

The range of mandibular abduction was satisfactory for all patients. It was between 45 and $54 \mathrm{~mm}$ between the incisors of dental arches or dentures. This gave an average value of $49.23 \mathrm{~mm}$ with a 
standard deviation of $2.75 \mathrm{~mm}$. The numbers of patients presenting individual mouth opening values are shown in Figure 10.

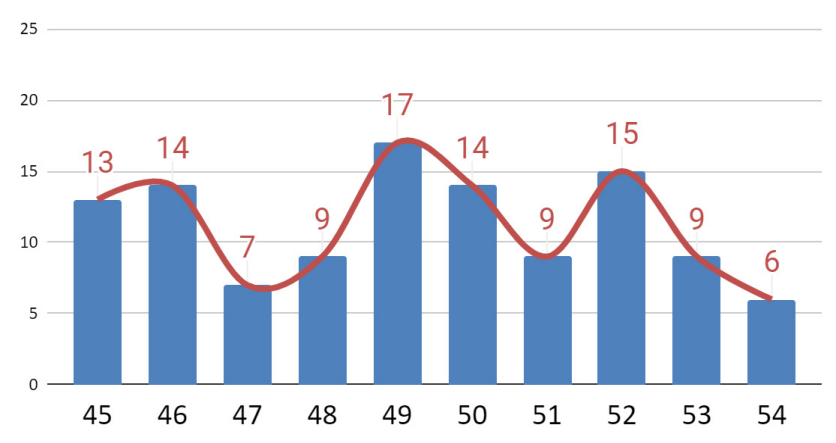

Figure 10. Distribution of patients depending on the amplitude of mouth opening.

No fractures of osteosynthesis plates were found in any of the cases. Therefore, the healing of bone fragments has not been disrupted in any of the cases. However, in four out of 113 (3.5\%) patients, loosening of one or more of osteosynthesis screws was observed (Figures 11-14).

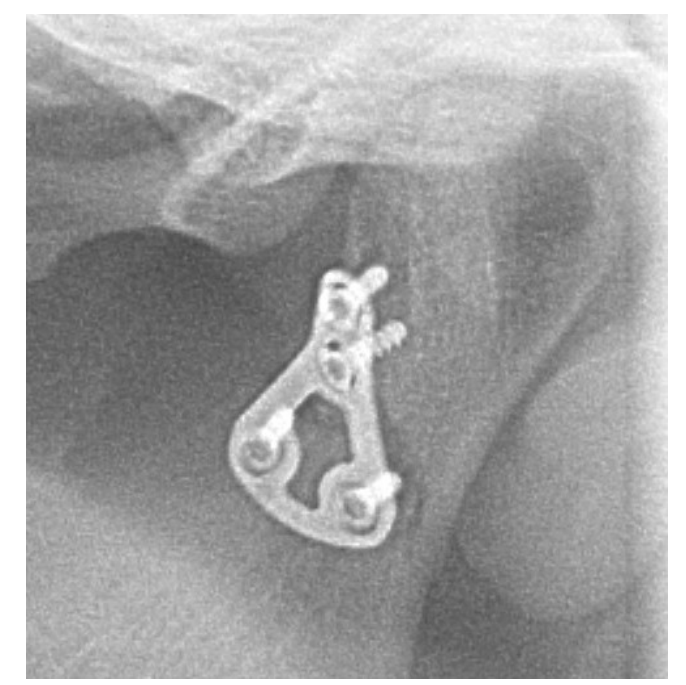

Figure 11. Patient A—An uncomplicated case—immediately after open reduction and internal fixation.

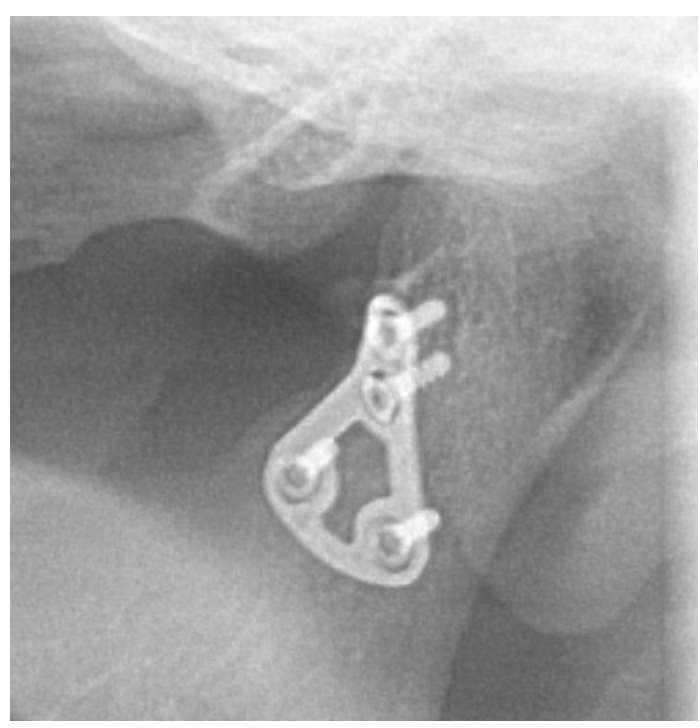

Figure 12. Patient A-An uncomplicated case -6 months after the surgery. 


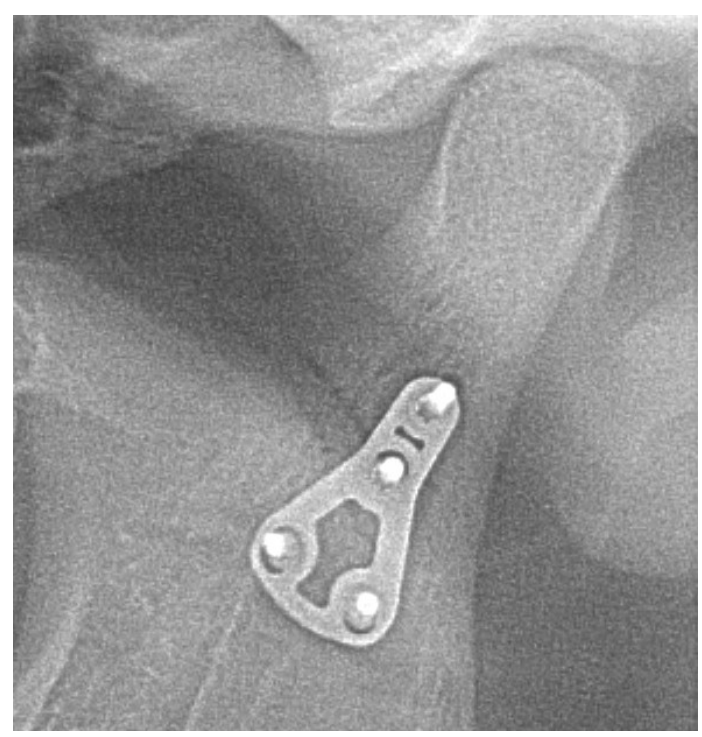

Figure 13. Patient B-A case complicated by screw loosening-immediately after open reduction and internal fixation.

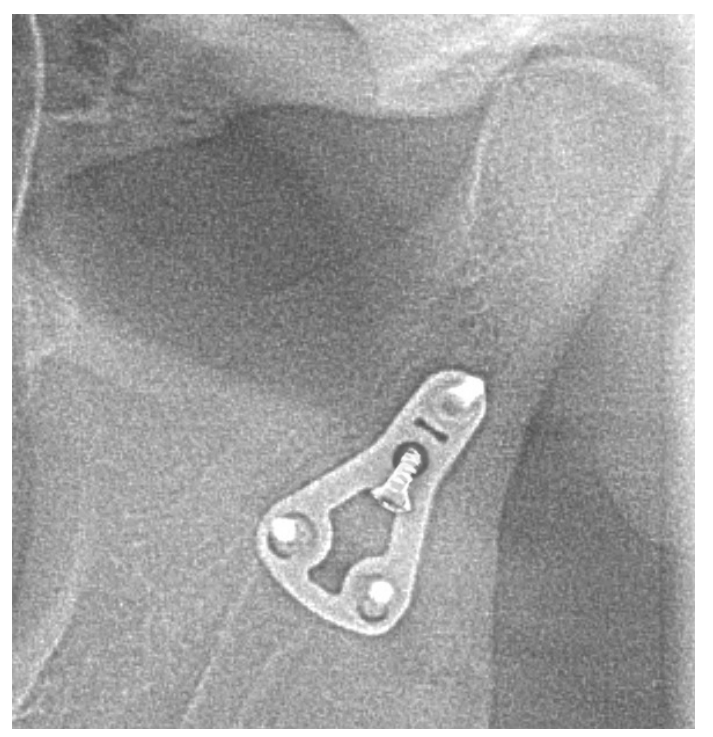

Figure 14. Patient B-A case complicated by screw loosening -6 months after the surgery.

Malocclusion, which had to be corrected by orthodontic treatment, prosthetic treatment or a combination of those, occurred in 6 out of $113(5.3 \%)$ patients. Almost $90 \%$ of the respondents did not have any complaints regarding the temporomandibular joint. In a further 11 of $113(9.7 \%)$ patients, the transient ailments passed within 6 months of surgery.

The total rate of various complications in our study group was $25.7 \%$. It means that 28 out of 113 operated patients developed one of the following complications: temporary hypofunction of the facial nerve, loosening of the screw, presence of occlusal disorders, presence of temporomandibular joint disorders.

\section{Discussion}

As already mentioned in the introduction to this paper, the qualification of patients for closed and open treatment is difficult and controversial $[9,10,29]$. In the study group, we performed surgical treatment in cases of occlusal disorders, comminuted fractures, dislocation within temporomandibular joint or lack of contact between bone fragments. Such rules are generally known and widely 
accepted $[2,6]$. The biggest qualifying problem is caused by cases where the fracture gap is single and the circumstances described above do not occur. In such situations, the criterion for qualifying for surgical treatment was shortening the mandible branch by 4 or more millimeters. However some authors suggest open treatment in cases of even smaller displacements, i.e., from $2 \mathrm{~mm}$ [30].

English literature lacks assessments based on large groups of patients regarding surgical treatment of fractures of the base and neck of the mandible condyle. To our knowledge, this study is the second largest, in terms of number of patients, indexed in the PubMed database of articles assessing the results of treatment using 3D plates. An exceptionally extensive study was conducted by Louvrier et al. on a group of 434 patients in the years 2006-2018 and published in 2020 [31]. The remaining similar studies from the last 10 years were conducted on 10 to 42 patients in the study group $[7,15,32,33]$.

Among the patients from the aforementioned study, Louvrier et al. in $97.6 \%$ of cases use TCPs. In our material in $79.6 \%$ of cases it was decided to use DCCPs, and in $14.2 \%$ to TCPs. In other cases, more than one plate was used. We did not use the single straight or L-shaped plate technique knowing convincing arguments about the poor quality of such fixation [14,15]. According to clinical studies, the use of two miniplates gives good results, but it has a serious disadvantage of having to insert a minimum of 3-4 screws in the proximal bone fragment [14,15]. The use of a TCP allows insertion of 2 or more screws in a smaller fraction. Insertion of a larger number of screws is possible when a larger TCP size is used and depends on the size of the proximal fragment and bone quality. The difference between a small TCP and DCCP is due to the hole pattern for fixing the two screws. In the case of DCCP their arrangement is linear, in our opinion more suitable for stable fixation of the narrow neck of the mandible [7]. To prevent adverse mechanical factors resulting from the linear arrangement of the holes in the DCCP, a compression profiling of these holes was designed [7,15]. A common feature for various $3 \mathrm{D}$ plates shapes is their ease of adaptation to bone shape and application in place of bone fracture. According to our and other researchers, these features reduce the time of surgery $[7,15]$.

Mandible abduction in our study group reached an average value of $49.2 \mathrm{~mm}$ and a median of $49 \mathrm{~mm} 6$ months after surgery. No correlation was observed between this value and other examined factors. Considering the constant discussion on how to treat condyle fractures in cases of slight displacement, it is worth referring to the study of Asim et al. These authors observed that after 6 months, 40 patients treated surgically showed a statistically significant larger mouth opening by about $3 \mathrm{~mm}$ than 40 others treated with closed methods [34]. In the group of studies including 6-month observation or longer, average values of mouth opening after open treatment are given in the range from 36.4 to $44.0 \mathrm{~mm}$ [34-36]. These studies concerned various surgical approaches (including endoscopic), and various fixation materials. With this in mind, the greater range of mouth opening obtained in our material is probably related with early mobilizing patients jaw opening just after the surgery.

The authors of this work have not yet encountered the case of a 3D plate fracture in their practice. Other authors who tested 3D plates on animals and clinically also did not notice any fractures $[7,15,37]$. In turn, loosening of osteosynthesis screws occurs in patients treated with the use of one miniplate in approximately $13 \%$ to $19 \%$ of cases, and a higher percentage of this complication was observed for 3D plates $[38,39]$. These percentages were calculated for the groups where loosening of the screws even occurred. In the case of the large study group analyzed by us, this percentage is clearly lower, which may be a fair average between the groups without this complication and the above-mentioned ones. The percentage of patients with loose osteosynthesis screws was 3.5\% in our material. Three out of four patients with loose screws were diagnosed with comminuted fractures, which may be related. In the case shown in Figures 13 and 14, the proximity of the fracture gap could have caused the screw loosening. Zrounba et al. note that the likelihood of loosening of osteosynthesis screws increases in cases of higher fracture lines and bilateral fractures [40]. In our opinion, the right choice of 3D miniplate allows for proper placement of its holes on the bone surface, which reduces the percentage of loosening screws [7]. 
Ahuja et al. found directly after surgery $30 \%$ of occlusal disorders in a group of 10 patients treated with Delta plates and $40 \%$ in 10 patients in whom conventional mini plates were used. After a month, these authors obtained the correct occlusion in the entire 3D plates group. Malocclusion persisted in one patient in the group of conventional miniplates due to non-reduced concomitant fracture [15]. Pappachan et al. treated two groups of five patients using one and two L-shaped mini plates, respectively. Malocclusion after 3 months occurred in $60 \%$ only in the group treated with one mini-plate [14]. In the study of Yang et al. two of $36(5.6 \%)$ patients surgically treated for fractures of the neck or condyle base had persistent occlusion disorders one year after surgery [41]. In our study, occlusal conditions were carefully monitored in the postoperative period. If required, a flexible maxillo-mandibular fixation was used. Despite this, in $5.3 \%$ of patients we were unable to achieve primary occlusion using surgical, orthopedic and functional therapy methods. In these cases, we ordered orthodontic or prosthetic treatment or a combination of them. When assessing the percentage of occlusal disorders in the material of other researchers, it should be taken into account that patients presenting e.g., comminuted fractures, other mandible fractures or non-mandible injuries were excluded from the studies referred to earlier, depending on their qualification criteria $[14,15]$. Our material involved $67.3 \%$ of patients with concomitant fractures of other parts of the mandible.

Among 113 patients included in our study, $13(11.5 \%)$ reported complaints related to temporomandibular joints. In two patients $(1.8 \%)$, temporomandibular disorders did not resolve within 6 months and had to be referred for further diagnosis and treatment. The first of these two patients had multiple mandible fractures and extensive trauma to other facial bones and soft tissues. Furthermore he was operated over 10 days after the injury. The second patient suffered from a multiple-site mandible fracture. Fracture of the condyle itself was comminuted, displaced and dislocated. In addition, the patient smoked over 20 cigarettes a day and often consumed alcohol. For comparison, Yang et al. report $5.6 \%$ and $19.4 \%$ respectively of pain and acoustic symptoms from the temporomandibular joints in a group of 36 patients examined one year after surgery [41]. After the same observation time, Yang and Patil noticed clicking in $8 \%$ of the 40 joints examined after open treatment of fractures of mandible condyles [36].

\section{Conclusions}

1. 3D titanium mini-plates are easy to adjust and take up little space, that's why it can be widely used in cases of mandibular condyle fractures.

2. Stability of 3D osteosynthesis materials (no cases of plates breaking and low percentage of screws loosening) gives very good reliability for rigid fixation of bone fragments.

Author Contributions: Conceptualization: M.S. (Maciej Sikora) and D.C.; Data Curation: M.S. (Maciej Sikora) and M.S. (Marcin Sielski); Investigation: M.S. (Maciej Sikora), M.C., and M.S. (Marcin Sielski); Writing-Original Draft: M.S. (Maciej Sikora), M.C. and D.C.; Writing-Review \& Editing: M.S. (Maciej Sikora), M.C. and D.C.; Supervision: D.C.; Funding Acquisition: D.C.; Overall Responsibility: M.S. (Maciej Sikora) and D.C. All authors have read and agreed to the published version of the manuscript.

Funding: This research received no external funding.

Conflicts of Interest: The authors declare no conflict of interest.

\section{References}

1. Kozakiewicz, M. Classification proposal for fractures of the processus condylaris mandibulae. Clin. Oral Investig. 2018, 23, 485-491. [CrossRef] [PubMed]

2. Neff, A.; Cornelius, C.-P.; Rasse, M.; Torre, D.D.; Audigé, L. The Comprehensive AOCMF Classification System: Condylar Process Fractures—Level 3 Tutorial. Craniomaxillofacial Trauma Reconstr. 2014, 7, 44-58. [CrossRef] [PubMed]

3. Loukota, R.; Eckelt, U.; De Bont, L.; Rasse, M. Subclassification of fractures of the condylar process of the mandible. Br. J. Oral Maxillofac. Surg. 2005, 43, 72-73. [CrossRef] [PubMed] 
4. Xiao-Dong, L.; Qiu-Xu, W.; Wei-Xian, L. Epidemiological pattern of maxillofacial fractures in northern China. Medicine 2020, 99, e19299. [CrossRef]

5. Bhutia, D.P.; Singh, G.; Mohammed, S.; Ram, H.; Gamit, J.; Howlader, D. Prevalence and Etiology of Pediatric Maxillofacial Injuries: A Unicenter-based Retrospective Study. Int. J. Clin. Pediatr. Dent. 2019, 12, 528-531. [CrossRef]

6. Sikora, M.; Olszowski, T.; Chlubek, D. Current views on the treatment of condylar fractures. Pomeranian J. Life Sci. 2018, 64, 14-23.

7. Sikora, M.; Sielski, M.; Stapor, A.; Chlubek, D. Use of the Delta plate for surgical treatment of patients with condylar fractures. J. Cranio-Maxillofac. Surg. 2016, 44, 770-774. [CrossRef]

8. Sikora, M.; Olszowski, T.; Sielski, M.; Stapor, A.; Janiszewska-Olszowska, J.; Chlubek, D. The use of the transparotid approach for surgical treatment of condylar fractures-Own experience. J. Craniomaxillofac. Surg. 2015, 43, 1961-1965. [CrossRef]

9. Moin, A.; Shetty, A.D.; Archana, T.; Kale, S.G. Facial Nerve Injury in Temporomandibular Joint Approaches. Ann. Maxillofac. Surg. 2018, 8, 51-55. [CrossRef]

10. Nussbaum, M.L.; Laskin, D.M.; Best, A.M. Closed Versus Open Reduction of Mandibular Condylar Fractures in Adults: A Meta-Analysis. J. Oral Maxillofac. Surg. 2008, 66, 1087-1092. [CrossRef]

11. Shakya, S.; Zhang, X.; Liu, L. Key points in surgical management of mandibular condylar fractures. Chin. J. Traumatol. 2020, 23, 63-70. [CrossRef] [PubMed]

12. Kozakiewicz, M.; Zieliński, R.; Konieczny, B.; Krasowski, M.; Okulski, J. Open Rigid Internal Fixation of Low-Neck Condylar Fractures of the Mandible: Mechanical Comparison of 16 Plate Designs. Materials 2020, 13, 1953. [CrossRef] [PubMed]

13. Zieliński, R.; Kozakiewicz, M.; Konieczny, B.; Krasowski, M.; Okulski, J. Mechanical Evaluation of Titanium Plates for Osteoesynthesis High Neck Condylar Fracture of Mandible. Materials 2020, 13, 592. [CrossRef]

14. Pappachan, B.; Agrawal, R. Comparison of two L shaped Plate on Plate Versus Single Conventional L Miniplate in Fixation of Subcondylar Mandibular Fractures. J. Maxillofac. Oral Surg. 2018, 18, 440-446. [CrossRef] [PubMed]

15. Ahuja, S.; Galinde, J.; Asnani, U.; Mistry, Y.A. Comparative Evaluation of Clinical Outcomes Using Delta Plates and Conventional Miniplates for Internal Fixation of Mandibular Condylar Fractures in Adults. J. Oral Maxillofac. Surg. 2018, 76, 1255-1266. [CrossRef] [PubMed]

16. Kozakiewicz, M.; Zieliński, R.; Krasowski, M.; Okulski, J. Forces Causing One-Millimeter Displacement of Bone Fragments of Condylar Base Fractures of the Mandible after Fixation by All Available Plate Designs. Materials 2019, 12, 3122. [CrossRef] [PubMed]

17. Albogha, M.H.; Mori, Y.; Takahashi, I. Three-dimensional titanium miniplates for fixation of subcondylar mandibular fractures: Comparison of five designs using patient-specific finite element analysis. J. Cranio-Maxillofac. Surg. 2018, 46, 391-397. [CrossRef]

18. Kozakiewicz, M.; Swiniarski, J. “A” shape plate for open rigid internal fixation of mandible condyle neck fracture. J. Cranio-Maxillofac. Surg. 2014, 42, 730-737. [CrossRef]

19. Zieliński, R.; Kozakiewicz, M.; Swiniarski, J. Comparison of Titanium and Bioresorbable Plates in "A" Shape Plate Properties-Finite Element Analysis. Materials 2019, 12, 1110. [CrossRef]

20. McLeod, N.; Van Gijn, D. Use of ultrasound-activated resorbable sheets and pins in the management of fractures of the condylar neck of the mandible: A case series. Br. J. Oral Maxillofac. Surg. 2018, 56, 182-185. [CrossRef]

21. Sikora, M.; Baranowska-Bosiacka, I.; Goschorska, M.; Chlubek, D. In vitro effect of three-dimensional (3D) titanium mini-plate systems used for surgical treatment of condylar fractures on interleukin 1 (IL-1) and interleukin 6 (IL-6) concentration in THP-1 macrophages. Tissue Cell 2020, 67, 101404. [CrossRef] [PubMed]

22. Sikora, M.; Baranowska-Bosiacka, I.; Lukomska, A.; Goschorska, M.; Chlubek, D. Expression of metalloproteinase 2 (MMP-2) and metalloproteinase 9 (MMP-9) in THP-1 macrophages cultured with three-dimensional titanium mini-plate systems used for surgical treatment of condylar fractures. Acta Biochim. Pol. 2019, 66, 291-298. [CrossRef] [PubMed]

23. Sikora, M.; Goschorska, M.; Baranowska-Bosiacka, I.; Chlubek, D. In Vitro Effect of 3D Plates Used for Surgical Treatment of Condylar Fractures on Prostaglandin E2 (PGE2) and Thromboxane B2 (TXB2) Concentration in THP-1 Macrophages. Int. J. Mol. Sci. 2017, 18, 2638. [CrossRef] [PubMed] 
24. Aquilina, P.; Parr, W.C.H.; Chamoli, U.; Wroe, S. Finite Element Analysis of Patient-Specific Condyle Fracture Plates: A Preliminary Study. Craniomaxillofacial Trauma Reconstr. 2015, 8, 111-116. [CrossRef] [PubMed]

25. Wilde, F.; Cornelius, C.-P.; Schramm, A. Computer-Assisted Mandibular Reconstruction using a Patient-Specific Reconstruction Plate Fabricated with Computer-Aided Design and Manufacturing Techniques. Craniomaxillofacial Trauma Reconstr. 2014, 7, 158-166. [CrossRef]

26. Zhou, Z.; Li, Z.; Ren, J.; He, M.; Huang, Y.; Tian, W.; Tang, W. Digital diagnosis and treatment of mandibular condylar fractures based on Extensible Neuro imaging Archive Toolkit (XNAT). PLoS ONE 2018, 13, e0192831. [CrossRef]

27. Krzewski, S.; Baranowski, M.; Zubrzycki, R.; Stachurski, M.; Borowicz, J. Correlation between temporomandibular joint dysfunction and Eichner classification. J. Educ. Heal. Sport 2020, 10, 155. [CrossRef]

28. Song, I.; Vong, J.; Yen, N.Y.; Diederich, J.; Yellowlees, P. Profiling Bell's Palsy based on House-Brackmann Score. J. Artif. Intell. Soft Comput. Res. 2013, 3, 41-50. [CrossRef]

29. Li, J.; Yang, H.; Han, L. Open versus closed treatment for unilateral mandibular extra-capsular condylar fractures: A meta-analysis. J. Cranio-Maxillofac. Surg. 2019, 47, 1110-1119. [CrossRef]

30. Schneider, M.; Erasmus, F.; Gerlach, K.L.; Kuhlisch, E.; Loukota, R.; Rasse, M.; Schubert, J.; Terheyden, H.; Eckelt, U. Open Reduction and Internal Fixation Versus Closed Treatment and Mandibulomaxillary Fixation of Fractures of the Mandibular Condylar Process: A Randomized, Prospective, Multicenter Study With Special Evaluation of Fracture Level. J. Oral Maxillofac. Surg. 2008, 66, 2537-2544. [CrossRef]

31. Louvrier, A.; Barrabé, A.; Weber, E.; Chatelain, B.; Sigaux, N.; Meyer, C.; Aurélien, L.; Aude, B.; Elise, W.; Brice, C.; et al. The high sub-mandibular approach: Our experience about 496 procedures. J. Stomatol. Oral Maxillofac. Surg. 2020, 20, 2468-7855. [CrossRef] [PubMed]

32. Smolka, W.; Liokatis, P.; Cornelius, C.-P. Open Reduction and Internal Fixation of Unilateral Mandibular Condylar Base and Neck Fractures Using a Lambda Plate: Selection Criteria for Application. J. Oral Maxillofac. Surg. 2020, 78, 979-985. [CrossRef]

33. Lechler, C.; Probst, F.; Cornelius, C.-P.; Smolka, W. Open Reduction and Internal Fixation of Mandibular Condylar Base and Neck Fractures Using Strut Plates. J. Oral Maxillofac. Surg. 2018, 76, 1494-1503. [CrossRef] [PubMed]

34. Asim, M.A.; Ibrahim, M.W.; Javed, M.U.; Zahra, R.; Qayyum, M.U. Functional Outcomes of Open Versus Closed Treatment Of Unilateral Mandibular Condylar Fractures. J. Ayub Med. Coll. Abbottabad: JAMC 2019, 31, 67-71. [PubMed]

35. Anehosur, V.; Kulkarni, K.; Shetty, S.; Kumar, N.; Shetty, S. Clinical outcomes of endoscopic vs retromandibular approach for the treatment of condylar fractures-A randomized clinical trial. Oral Surg. Oral Med. Oral Pathol. Oral Radiol. 2019, 128, 479-484. [CrossRef]

36. Yang, L.; Patil, P.M. The retromandibular transparotid approach to mandibular subcondylar fractures. Int. J. Oral Maxillofac. Surg. 2012, 41, 494-499. [CrossRef]

37. Haim, D.; Müller, A.; Leonhardt, H.; Nowak, A.; Richter, G.; Lauer, G. Biomechanical Study of the Delta Plate and the TriLock Delta Condyle Trauma Plate. J. Oral Maxillofac. Surg. 2011, 69, 2619-2625. [CrossRef]

38. Rai, A. Comparison of single vs double noncompression miniplates in the management of subcondylar fracture of the mandible. Ann. Maxillofac. Surg. 2012, 2, 141-145. [CrossRef] [PubMed]

39. Lauer, G.; Pradel, W.; Schneider, M.; Eckelt, U. A New 3-Dimensional Plate for Transoral Endoscopic-Assisted Osteosynthesis of Condylar Neck Fractures. J. Oral Maxillofac. Surg. 2007, 65, 964-971. [CrossRef]

40. Zrounba, H.; Lutz, J.-C.; Zink, S.; Wilk, A. Epidemiology and treatment outcome of surgically treated mandibular condyle fractures. A five years retrospective study. J. Cranio-Maxillofac. Surg. 2014, 42, 879-884. [CrossRef]

41. Yang, W.-G.; Chen, C.-T.; Tsay, P.-K.; Chen, Y.-R. Functional Results of Unilateral Mandibular Condylar Process Fractures after Open and Closed Treatment. J. Trauma: Inj. Infect. Crit. Care 2002, 52, 498-503. [CrossRef]

(C) 2020 by the authors. Licensee MDPI, Basel, Switzerland. This article is an open access article distributed under the terms and conditions of the Creative Commons Attribution (CC BY) license (http://creativecommons.org/licenses/by/4.0/). 